DOI: $10.12731 / 2306-1561-2013-4-6$

\title{
STUDY OF PROBLEMS OF ORGANIZATION OF KNOWLEDGE IN THE FIELD OF INFORMATION TECHNOLOGY
}

\author{
Belousova A.I., Pavlov D.A.
}

\begin{abstract}
The paper analyzes the evolution of decision support systems. An approach to the development of intelligent system handling of knowledge, which will reduce the time of finding relevant information, will increase the accuracy of the information, provide the ability to analyze the information at different levels of decision-making, ensure efficiency and accessibility of information.
\end{abstract}

Keywords: management, modeling, information environment, automated control systems, decision support, information technology, business processes, Customer Relationship Management (CRM).

\section{УДК 004.9}

\section{ИССЛЕДОВАНИЕ ПРОБЛЕМ ОРГАНИЗАЦИИ ЗНАНИЙ В ОБЛАСТИ ИНФОРМАЦИОННЫХ ТЕХНОЛОГИЙ}

\section{Белоусова А.И., Павлов Д.А.}

\section{Аннотация}

B статье анализируется эволючия развития систем поддержки принятия решений. Предложен подход к разработке интеллектуальной системы, оперирующей знаниями, которая позволит снизить время поиска нужной информации, повысит достоверность информации, обеспечит возможность анализа информации на разных уровнях принятия решений, обеспечит оперативность и доступность информации.

Ключевые слова: управление, моделирование, информационная среда, автоматизированные системы управления, системы поддержки принятия решения, информационные технологии, бизнес-прочессы, CRM - системы.

\section{Введение}

Системы поддержки направлены на повышение эффективности работы предприятий при использовании прикладного программного обеспечения. Они позволяют учитывать особенности каждого предприятия, важен индивидуальный подход к организации деятельности того или иного предприятия. Используя систему 
поддержки, предприятие ставит перед собой какую-либо цель, например, повышение эффективности работы сотрудников или увеличение прибыли и т.д. [1] На протяжении всей своей деятельности то или иное предприятие накапливает множество знаний: опыт, информацию, идеи, отношения. Именно грамотное управление знаниями, возникающими в процессе теоретической и практической деятельности сотрудников, позволяет достичь цели, которую ставит перед собой предприятие [2].

Целью работы является исследование проблемы организации знаний в области информационных технологий. Рассмотрение вопроса организации знаний и анализ процесса осуществления поиска по ним в системе «Поддержка клиентов». Также работа направлена на то, чтобы показать важность организации знаний на предприятии.

\section{Эволюция развития систем поддержки принятия решений}

Системы поддержки принятия решений стремительно развивались и прошли следующий путь: от систем обработки транзакций до экспертных систем. Интеграция компьютерных информационных систем представлена на рисунке 1 и таблице $1[8,9]$.

\section{Экспертные системы ES 1980}

Системы поддержки решений DDS 1980

Системы автоматизации конторской деятельности OAS

Автоматизированные системы управления MIS 1960

\section{Системы обработки транзакций TSP 1950}

\section{Рисунок 1 - Развитие систем автоматизированного управления и систем поддержки принятия решений}

Экспертная система считается вершиной развития информационных систем и является разновидностью систем поддержки DDS, которая предназначена для достижения цели, поставленной руководством.

Система поддержки клиентов, разработанная в ЗАО «Информационные технологии» - это экспертная система, целью которой было ускорить процесс работы с заявками. 
Таблица 1 - Сравнительный анализ экспертной системы и системы поддержки решений DDS

\begin{tabular}{|c|c|c|}
\hline Цель & $\begin{array}{l}\text { Помощь лицу, принимаюшему } \\
\text { решение в принятии решения }\end{array}$ & $\begin{array}{c}\text { Имитирование деятельности } \\
\text { людей-экспертов }\end{array}$ \\
\hline Кто принимает решение? & ЛПР и (или) система & Система \\
\hline Главная ориентация & Принятие решений & $\begin{array}{c}\text { Передача экспертизы } \\
\text { (эксперт-компьютер-человек), } \\
\text { тиражирование экспертизы }\end{array}$ \\
\hline $\begin{array}{l}\text { Кто преимущественно } \\
\text { задает вопросы }\end{array}$ & ЛПР & Компьютер \\
\hline Объект поддержки & Лица, группы лиц, организации & Лица и группы лиц \\
\hline $\begin{array}{l}\text { какой информацией } \\
\text { преимущественно } \\
\text { манипулируют }\end{array}$ & Числовой & Символьной \\
\hline $\begin{array}{l}\text { Характеристика } \\
\text { проблемной области }\end{array}$ & Комплексная, широкая, сложная & Узкая \\
\hline Тип задач & Случайные, уникальные & Повторяющиеся \\
\hline Содержание базы данных & Фактические значения & $\begin{array}{c}\text { Процедурные и фактические } \\
\text { знания }\end{array}$ \\
\hline \begin{tabular}{|l|} 
Способность $\quad$ проводить \\
логические рассуждения \\
\end{tabular} & Нет & Да, ограниченная \\
\hline $\begin{array}{l}\text { Возможность получения } \\
\text { объяснений }\end{array}$ & Ограниченная & Да \\
\hline
\end{tabular}

\section{Система «Поддержка клиентов»}

Система «Поддержка клиентов» - это реальная система, разработанная на предметно-ориентированном языке программирования 1С и проходящая в настоящее время опытную эксплуатацию на предприятии (рисунок 2).

Основные вопросы, которые стояли перед разработчиками при разработке системы:

1. Прием и фиксация всех обращений клиентов, как по телефону, так и по е mail или через самостоятельную регистрацию заявки на сайте.

2. Поиск по выполненным заявкам информации для более быстрого поиска решения по текущей заявке.

3. Прикрепление файлов к заявке для пояснения ситуации.

4. Отслеживание выполнения заявки - кто, когда, что делал с заявкой и ее текущее выполнение.

5. Фиксация времени работы над заявкой.

6. Создание уровней поддержки - Прием заявки -> Передача ее на первый уровень (если задача не решена на этапе приема) -> Передача на второй уровень, если задача не может быть решена на первом уровне 
7. Возможность переадресации заявки между сотрудниками.

8. Оповещение пользователя о решении его заявки.

9. Фиксация состояния и количества баз данных у клиентов (степень настроенности).

10. Фиксация последних установленных релизов.

11. Хранение в базе данных информации для удаленного доступа к клиенту.

12. Хранение и поддержка в актуальном состоянии информации о настройках в базах, в том числе конфигурационных файлов и внешних отчетов.

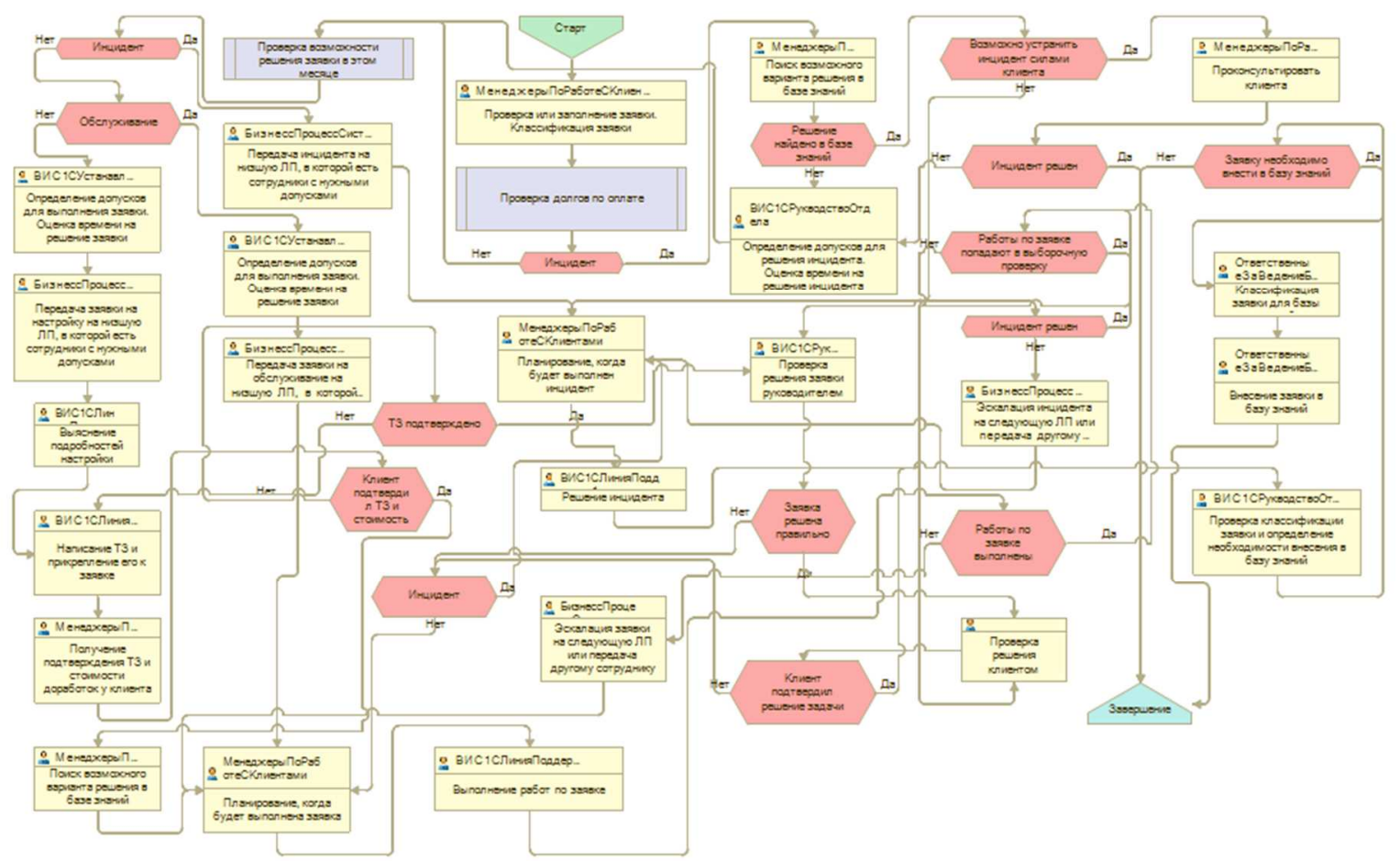

Рисунок 2 - Карта маршрута бизнес - процесса «Заявка на обслуживание 1С»

1 линия поддержки - это специалисты широкого профиля. 2 линия поддержки это специалисты узкого профиля, которые получают инциденты от первой линии при невозможности их решения на предыдущем уровне. В основе данной системы лежит многоуровневый принцип, что позволяет не отвлекать более квалифицированных специалистов на решение задач, которые могут решить менее квалифицированные специалисты и обеспечить равномерную загрузку для менее квалифицированных специалистов.

Данный принцип имеет недостаток - это увеличенное время решения проблемы, например, если проблемой занимается специалист первой линии поддержки, который впервые столкнулся с ней, что значительно увеличивает время ее решения. При невозможности ее решения, проблема экскалируется более квалифицированному специалисту.

Для решения данного недостатка необходимо, в случае отсутствия в базе знаний решения выбирать уровень поддержки в зависимости от сложности проблемы или 
конкретного специалиста, который ранее занимался решением похожей проблемы, что позволит ускорить процесс работы с заявками.

Система поддержки принятия решения по выбору нужной линии поддержки и специалиста должна опираться на данные базы знаний, но производить не прямой поиск по классификации инцидентов или по совпадению слов, а искать похожие инциденты. На основе анализа, на какой линии поддержки решались эти инциденты и каким сотрудником, выдавать рекомендации оператору для принятия окончательного решения.

Для организации поиска в базе знаний предлагается оперировать методом кластерного анализа и искусственной нейронной сетью, сначала необходимо проводить грубый отбор похожих инцидентов с помощью нейронной сети, а затем, с использованием большего количества влияющих факторов производить выделение кластеров.

Основная задача, которая стояла перед разработчиками - автоматизация процесса работы с клиентами. Важным процессом при работе с клиентом является процесс принятия его заявки и ее решение. В данной системе созданы бизнес процессы для обслуживания заявок клиентов, однако для них требуется продумать процесс организации знаний.

В результате, получилась система, которая хранит информацию по всем заявкам и производит поиск похожих заявок в базе знаний, что значительно ускоряет процесс закрытия заявок. Во многих случаях менеджеру удается проконсультировать и решить проблему клиента по телефону, также многие инциденты могут решить сотрудники первой линии поддержки, не обращаясь при этом ко второй линии поддержки.

\section{Представление знаний в интеллектуальных системах}

Выделяют следующие системы представления знаний [7 - 10]:

- фреймы;

- исчисления предикатов;

- системы продукций;

- семантические сети;

- нечеткая логика.

В качестве системы представления знаний, я выбрала систему продукций. Под продукцией будем понимать выражение:

$$
\begin{gathered}
\text { Если }<X 1, X 2 \ldots X n>m o \\
<\{Y 1, D 1\}, \ldots\{Y m, D m\}>,
\end{gathered}
$$

где: $\mathrm{Xi}, \mathrm{Yi}$ - логические выражения, Di - фактор достоверности $(0,1)$ или фактор уверенности $(0,100)$. [5]

Системы продукций - это набор правил, которые применяются в качестве базы знаний, называемый также базой правил. В Стэндфордской теории фактор уверенности 
$\mathrm{CF}$ (certainty factor) принимает значения от +1 (максимум доверия к гипотезе) до 1 (минимум доверия). [3]

А.Ньюэлл и Г.Саймон отметили в GPS(Global Position System), что продукции аналогичны навыкам решения задач человеком в долгосрочной памяти человека и при работе системы данные продукции не изменяются подобно навыкам в долгосрочной памяти [7 - 9]. Для решения проблемы вызываются они по «образцу». Рабочая память продукционной системы схожа с краткосрочной памятью человека. Содержание рабочей области после решения задачи не сохраняется [4].

Работу продукционной системы инициирует начальное описание задачи. Далее, из продукционного множества правил выбираются лишь те правила, которые пригодны для дальнейшего применения. Эти правила создают конфликтное множество, для выбора этих правил из конфликтного множества применятся различные стратегии разрешения конфликтов, которые либо достаточно простые, либо это сложные эвристические правила.

Продукционная модель, как таковая, не имеет механизма выхода из нерешаемых состояний в процессе поиска. Она работает до тех пор, пока не исчерпаются все продукции, которые доступны. На практике реализации продукционных систем содержат механизмы возврата в предыдущее состояние для управления алгоритмом поиска $[5,9]$.

\section{Поиск по базе знаний}

Поиск похожих вариантов решения заявки может осуществляться либо по определенным разделам, либо по всей базе знаний. Для того чтобы организовать автоматическое хранение информации, используется стемматизация, нахождение слов по корню слова.

На общей схеме поиска направления эскалации инцидента (рисунок 3, [6]) показана последовательность поиска линии поддержки и сотрудника, который сможет наиболее квалифицировано и быстро решить инцидент, который невозможно решить на первой линии поддержки с помощью простого запроса к базе знаний.

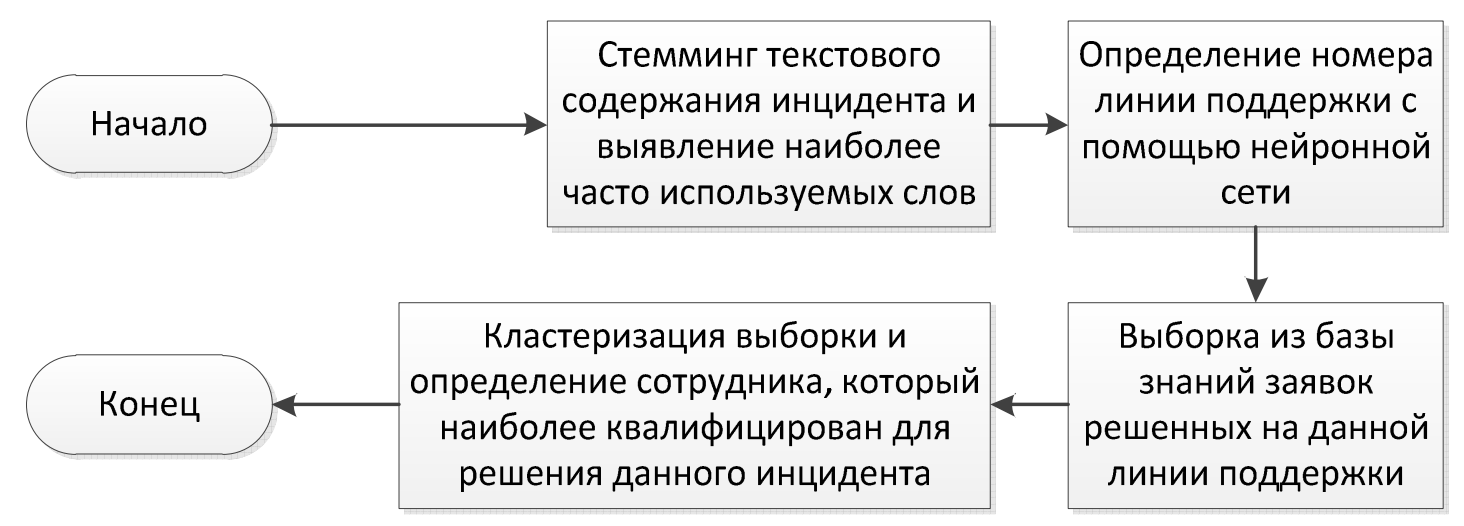

Рисунок 3 - Общая схема поиска направления эскалации инцидента 


\section{Заключение}

Использование знаний и управление ими имеет множество преимуществ. В работе было проанализировано, что собой представляют система поддержки, управление знаниями, рассмотрена система поддержки клиентов, поиск по базе знаний. Создание такой интеллектуальной системы, оперирующей знаниями, позволит снизить время поиска нужной информации, повысит достоверность информации, обеспечит возможность анализа информации на разных уровнях принятия решений, обеспечит оперативность и доступность информации (возможность доступа к системе через интернет).

\section{Список информационных источников}

[1] Белоусова А.И. Подход к формированию многоуровневой модели мультиагентной системы с использованием миваров / А.В. Остроух, А.И. Белоусова, М.Н. Краснянский, О.О. Варламов // Перспективы науки. - 2011. - № 5(20). - С. 57 - 61.

[2] Николаев А.Б. Информационные технологии в менеджменте и транспортной логистике: учебное пособие / А.Б. Николаев, А.В. Остроух. - Saint-Louis, MO, USA: Publishing House Science and Innovation Center, 2013. - 254 c. - ISBN 978-0615-67110-9.

[3] Остроух, А.В. Информационные технологии в научной и производственной деятельности / [ред. А.В. Остроух] - М: ООО "Техполиграфцентр", 2011. - 240 с. ISBN 978-5-94385-056-1.

[4] Остроух, А.В. Основы построения систем искусственного интеллекта для промышленных и строительных предприятий / А.В. Остроух - М.: ООО «Техполиграфцентр», 2008. - 280 с. - ISBN 978-5-94385-033-2.

[5] Остроух А. В., Суркова Н. Е. Методы проектирования информационных систем: учебное пособие. - М.: РосНОУ, 2004. - 144 с.

[6] Павлов Д.А. Система поддержки принятия решений для повышения эффективности распределения заявок между сотрудниками и уменьшения времени требуемого для решения инцидентов в системах service desk. - M. 2011. C. 4-7.

[7] Поспелов Д.А. О «человеческих» рассуждениях в интеллектуальных системах // Логика рассуждений и ее моделирование. Научный совет по комплексной проблеме «Кибернетика» при Президиуме АН СССР. - М., 1983. - С. 5-37.

[8] Робинсон Дж. Машинно-ориентированная логика, основанная на принципе резолюции // Кибернетический сборник. Новая серия. - М.: Мир, 1970. - Вып. 7. C. 194-218.

[9] Суркова Н.Е., Угарова Ю.Н. Организация работы ит-подразделения в холдинговых структурах // Автоматизация и управление в технических системах. - 2013. - № 1(3); URL: auts.esrae.ru/3-59 (дата обращения: 31.10.2013).

[10] Уинстон П. Искусственный интеллект. - М.: Мир, 1980. - 519 с.

[11] Черняк Л. Управление знаниями и информационные технологии // Открытые системы. - 2000. - №10.

[12] Юрчик П.Ф. Формализация задач принятия решений при управлении проектами обеспечения жизненного цикла автодорожных объектов / П.Ф. Юрчик, А.В. Остроух А.Г. Соленов, И.Н. Акиньшина // Приборы и системы. Управление, контроль, диагностика. - М.: «Научтехлитиздат», 2007. - №3. - С. 13-18. 
МАТЕРИАЛЫ ІХ МЕЖДУНАРОДНОЙ ЗАОЧНОЙ НАУЧНО-ПРАКТИЧЕСКОЙ КОНФЕРЕНЦИИ МОЛОДЫХ УЧЕНЫХ «ТЕОРИЯ И ПРАКТИКА ПРИМЕНЕНИЯ ИНФОРМАЦИОННЫХ ТЕХНОЛОГИЙ В ПРОМЫШЛЕННОСТИ И НА ТРАНСПОРТЕ», г. Москва, 12 ноября 2013 г.

[13] Юрчик П.Ф., Нестеренко В.И., Павлов Д.А., Рогова О.Б. Автоматизация поддержки принятия решений по обеспечению бескризисой работы промышленного предприятия: монография. - М.: ООО «Техполиграфцентр», 2006. $-197 \mathrm{c}$. 